\title{
Simulation and Test Analysis on Effect of Current Density on Electrodepositing Minuteness Structure under Supercritical Fluids
}

\author{
Haifeng QIAN ${ }^{1}$, Weining LEI ${ }^{1}$, Weiqiao LIU ${ }^{1}$, Caoyang GU ${ }^{2}$ \\ ${ }^{1}$ Jiangsu University of Technology, Jiangsu Key Laboratory for Green Forming and Equipment of High-Performance \\ Materials, Changzhou 2l3001, China \\ 2 Jiangsu Union Technical Institute, Nantong 226400, China
}

crossref http://dx.doi.org/10.5755/j01.ms.24.2.17612

Received 17 February 2017; accepted 09 August 2017

\begin{abstract}
This study simulates the electric field of the supercritical electrodepositing system using Comsol software. The effects of the current density on the $\mathrm{Ni}^{2+}$ concentration distribution and the electrodepositing film growth on the cathodic surface are analyzed. The surface morphology and micro-hardness were discussed first. The results show that the electric field is uniformly distributed inside the minuteness groove. The average $\mathrm{Ni}^{2+}$ concentration on the cathodic surface decreases at first, but then increases with the proceeding electrodepositing process; the growth of the electrodepositing films is similar to the distribution of the cathodic current density. The grain size and organization of the Ni-diamond composite electrodepositing minuteness films under supercritical fluid are fine and compact. Moreover, the micro-hardness of the sample reaches $900.75 \mathrm{HV}(200 \mathrm{~g})$, a figure that is $70 \%$ higher than that of traditional electrodepositing when the current density is $700 \mathrm{~A} / \mathrm{m}^{2}$, the electrodepositing temperature is $323 \mathrm{~K}$, the supercritical pressure is $12 \mathrm{MPa}$, and the nano-diamond particles content is $30 \mathrm{~g} / \mathrm{L}$.

Keywords: supercritical fluid, electrodepositing, minuteness groove, simulation, surface morphology.
\end{abstract}

\section{INTRODUCTION}

In order to adapt to the special requirements of materials in current medical biology, aerospace, microelectro-mechanical systems (MEMS) and other fields, composite electrodepositing technology is often used for its unique ability to prepare high-performance precision metal matrix composites [1,2]. Technical limitations existing in the traditional composite electrodepositing technology including low mass transfer efficiency, mixing solubility, and low dispersion ability of ions, were solved by this technology under a supercritical fluid (SCF) $[3,6]$. The presence of supercritical composite electrodepositing technology has been reported [7, 8] but using supercritical composite electrodepositing technology to prepare micro films is reposted only on rare occasions.

For the basic research of this study $[8,9]$ in SCF condition, the metal ions and nano composite particles are given the high rate of diffusion and movement performance to supply the lack of metal ions and composite particles on the surface of cathode surface timely. At the same time the aggregation between composite particles is prevented due to the probability of collisions between composite particles reduced. The composite particles are better dispersed into the electroforming films. Then the electroforming film growth is more regular, the appearance of the supercritical electroforming film is smooth and the structure of the supercritical electroforming film is compact.

Comsol software was used to simulate the supercritical micro electrodepositing process to determine the influence of the current density on the micro film. The supercritical electrodepositing test was carried out accordingly. The influence of the current density on micro surface morphology and micro-hardness of the supercritical electrodepositing Ni-diamond films were analyzed.

\section{SIMULATION OF SCF-CO ELECTRODEPOSITING AND TEST CONDITIONS}

Comsol Multiphysics software simulated the $\mathrm{SCF}-\mathrm{CO}_{2}$ electrodepositing system to research the influence of the electric current density on the electrodepositing system. Then, tests were carried out accordingly.

In these tests, the anode was a pure nickel plate with dimensions $2.5 \mathrm{~cm} \times 3 \mathrm{~cm}$ and the cathode was a copper cone covering SU-8 photoresist microstructure with the size of $3 \mathrm{~cm}$ in diameter, $2 \mathrm{~cm}$ apart from the anode. Electrolyte composition and process conditions were as follows: nickel sulfate of $300 \mathrm{~g} / \mathrm{L}$, nickel chloride of $30 \mathrm{~g} / \mathrm{L}$, boric acid of $50 \mathrm{~g} / \mathrm{L}$, nano-diamond particles of $30 \mathrm{~g} / \mathrm{L}, 6$ drops of foaming agent per one hundred $\mathrm{ml}$, a working pressure of $12 \mathrm{MPa}$, working temperature of $323 \mathrm{~K}$, the current density of $500 \sim 900 \mathrm{~A} / \mathrm{m}^{2}, \mathrm{pH} 4$, a magnetic stirring speed of $400 \mathrm{r} \mathrm{min}^{-1}$, and a working time of $60 \mathrm{~min}$. The reagents used followed the AR (Analytical Reagent). Test method: the surface of the microstructure was characterized by Hitachi S-3400 (SEM) and the microhardness was tested by an HXD - 1000 TMS Digital Micro-hardness tester. The supercritical composite electrodepositing device is shown in Fig. 1.

\footnotetext{
* Corresponding author. Tel.: +0086-0519-86953061; fax: +0086-051986953200. E-mail address: leiweining@jsut.edu.cn (W. Lei)
} 


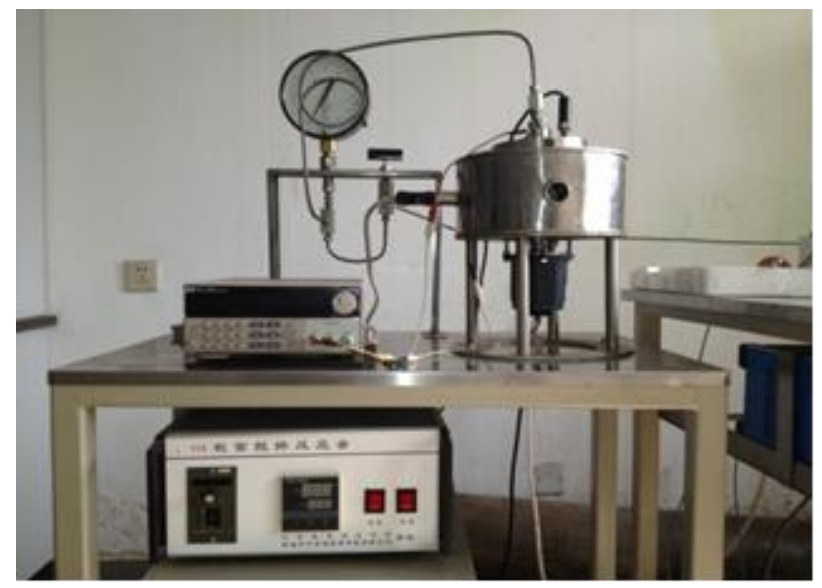

Fig. 1. The schematic of supercritical composite electrodepositing device

\section{THE ESTABLISHMENT OF MATHEMATIC- AL MODEL}

To simplify the studies, a geometrical model of the micro "cross" groove of the electro-deposition, shown in Fig. 2, was used. The cathode formed the bottom of the micro "cross" groove, and the electrolyte interface formed the top of the geometric model. These cross structures were fabricated using resist SU8.

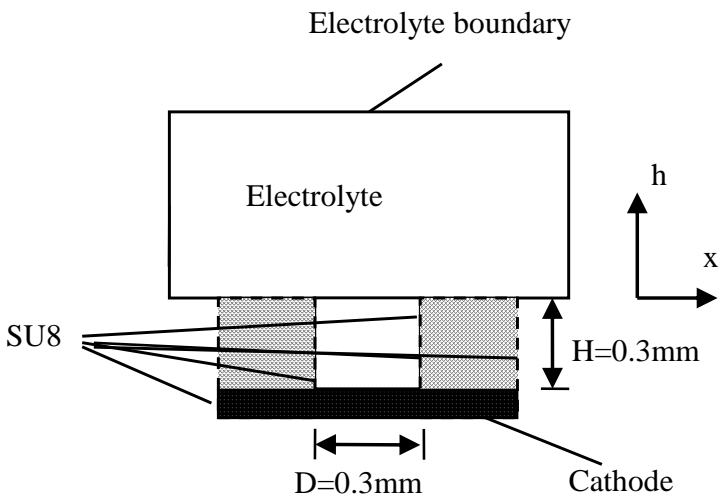

a

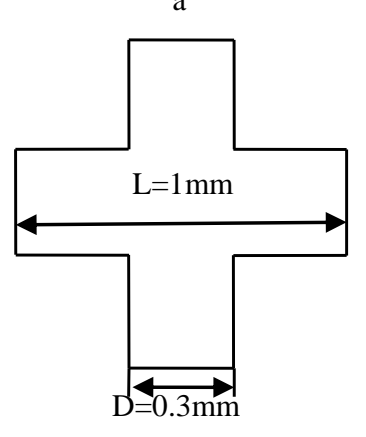

$\mathrm{b}$

Fig. 2. Geometry model of minuteness electrodepositing groove: $\mathrm{a}$-the micro electrodepositing unit; $\mathrm{b}$-size of cross structure

In order to streamline the model and improve the rate of convergence, the following assumptions were made: the micro electrodepositing system with constant electric field and cathodic steady current was adopted [10]; the applied voltage of the system was small enough to ignore ion transfer caused by electrophoresis; in the $\mathrm{SCF}-\mathrm{CO}_{2}$ environment, $\mathrm{Ni}^{2+}$ reduction precipitation was only considered on the cathode; $\mathrm{H}_{2}$ produced on the cathode quickly dissolved due to good solubility in the $\mathrm{SCF}-\mathrm{CO}_{2}$ electrodepositing environment; the influence of $\mathrm{H}_{2}$ on the nickel ion concentration distribution was ignored; diamond particles had no influence on the nickel deposition; the pressure and the temperature of the system was kept at 10 $\mathrm{MPa}$ and $323 \mathrm{~K}$, respectively. On this basis, the model of the $\mathrm{SCF}-\mathrm{CO}_{2}$ micro electrodepositing coupling field was constructed $[11,12]$.

\subsection{Model of electric field}

A model of the secondary current distribution was used. The cathodic potential deviated from the equilibrium value, an occurrence caused mainly by a slow electrochemical step because the diffusion coefficient of $\mathrm{Ni}^{2+}$ was great. Also, the ion concentration on the surface of the cathode could be supplemented effectively in the $\mathrm{SCF}-\mathrm{CO}_{2}$ system. The cathodic rate accorded with ButlerVolmer formula in electrodepositing process:

$$
I=I_{0}\left[\exp \left(\frac{\alpha_{A} \eta F}{R T}\right)-\exp \left(\frac{-\alpha_{c} \eta F}{R T}\right)\right],
$$

where $F$ denotes the Faraday constant, $R$ is the ideal gas constant, $I_{O}$ represents the exchange current density, $T$ is the absolute temperature, $\alpha_{A}, \alpha_{C}$ and $\eta$ are the charge transfer coefficient of the anode, the cathode, and the cathodic overpotential, respectively.

The electrolyte was of supercritical emulsified status. The boundary conditions of the electrode and the electrolyte interface are as follows: the electrolyte electric potential of the top boundary was $7 \mathrm{~V}$; the cathodic current density imposed to the bottom of the groove was $500 \mathrm{~A} / \mathrm{m}^{2}$, $700 \mathrm{~A} / \mathrm{m}^{2}, 900 \mathrm{~A} / \mathrm{m}^{2}$ and the electrical potential was zero.

\subsection{Model of $\mathrm{Ni}^{2+}$ diffusion and transfer}

Due to the fact that the $\mathrm{Ni}^{2+}$ reduction reaction was only considered on the cathode and that the mass transfer process was completed fully by diffusion, the following formula was obtained according to Fick's second law:

$$
\frac{\partial C(x, y, h, t)}{\partial t}=D \nabla^{2} C(x, y, h, t),
$$

where $D$ is the $\mathrm{Ni}^{2+}$ diffusion coefficient, $C(x, y, h, t)$ denotes the function of $\mathrm{Ni}^{2+}$ concentration.

In the $\mathrm{SCF}-\mathrm{CO}_{2}$ electrodepositing system, the $\mathrm{Ni}^{2+}$ diffusion coefficient was set at $3.11 \times 10^{-8} \mathrm{~m}^{2} / \mathrm{s}$. According to the electrolyte formula, the initial $\mathrm{Ni}^{2+}$ concentration was $1200 \mathrm{~mol} / \mathrm{m}^{3}$ and the top boundary was fixed at the initial $\mathrm{Ni}^{2+}$ concentration.

\section{SIMULATION ANALYSIS OF MICRO ELECTRODEPOSITING SYSTEM}

\subsection{Electric field analysis}

Fig. 3 displays the electric field distribution. The distribution of current density corresponds with the distribution of the electric field line. 


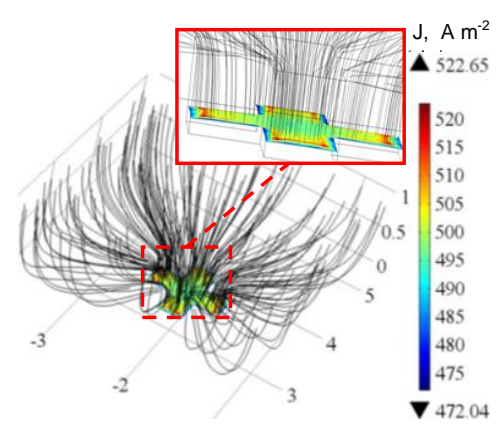

a

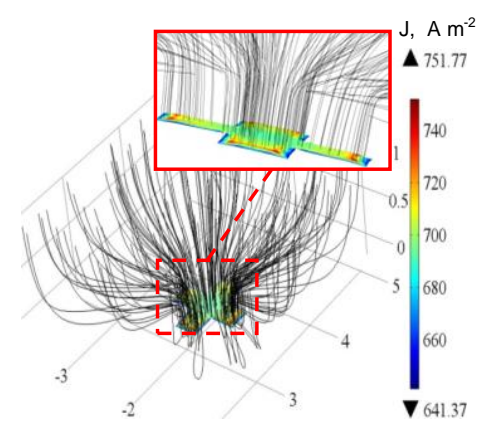

b

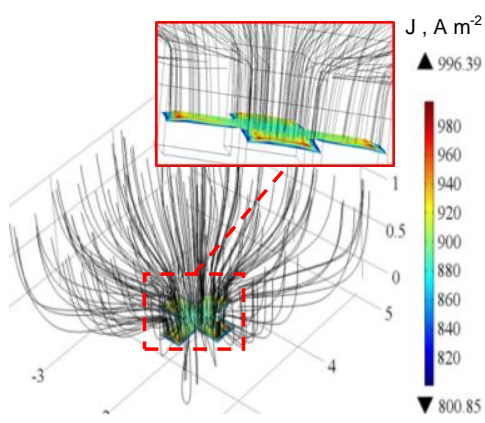

c

Fig. 3. Electric field distribution under different current density of $\mathrm{SCF}-\mathrm{CO}_{2}$ electrodepositing system: $\mathrm{a}-500 \mathrm{~A} / \mathrm{m}^{2} ; \mathrm{b}-700 \mathrm{~A} / \mathrm{m}^{2}$; $\mathrm{c}-900 \mathrm{~A} / \mathrm{m}^{2}$

From Fig. 3, it can be seen that the bending degree and consistency of the electric field line upon entering the micro groove increase gradually, the electric field intensity exhibits differences, and a potential gradient appears when the current density is $500 \mathrm{~A} / \mathrm{m}^{2}, 700 \mathrm{~A} / \mathrm{m}^{2}$ and $900 \mathrm{~A} / \mathrm{m}^{2}$. The electric field line is uniform and orthokinetic in the micro groove, indicating the steadiness and uniformity of the electric field distribution. With the increase of the current density from $500 \mathrm{~A} / \mathrm{m}^{2}$ to $900 \mathrm{~A} / \mathrm{m}^{2}$, the uneven trend of its distribution in the interface of the cathode and the electrolyte is more obvious. This is because the $\mathrm{Ni}^{2+}$ electrodepositing rate is different on the cathode surface due to the current edge effect, the mass transfer rate, and other factors. Then, the flatness of the electrodepositing film declines, the electrical current concentrates in partial region, and with the increase of current density, the flatness of electrodepositing film is even less likely to be controlled.

\section{2. $\mathrm{Ni}^{2+}$ concentration on the surface of electrodepositig film}

In the electrodepositing process, the $\mathrm{Ni}^{2+}$ concentration distribution on the surface is an important factor that affects the electrodepositing rate and the electrodepositing quality [13]. The average $\mathrm{Ni}^{2+}$ concentration under normal conditions and supercritical conditions can be seen respectively in Fig. 4. It can be seen that the $\mathrm{Ni}^{2+}$ concentration on the surface decreases dramatically in the beginning phase, but the decrease degree in the supercritical condition is much smaller. With the increase of the current density, the decrease degree of $\mathrm{Ni}^{2+}$ concentration enhances, causing the $\mathrm{Ni}^{2+}$ concentration to increase linearly. The higher current density is, the greater the slope is. The reasons are that the $\mathrm{Ni}^{2+}$ depositing rate on the cathode surface is great in the beginning phase, the internal $\mathrm{Ni}^{2+}$ concentration gradient forms newly, and the nickel ions precipitated on the cathode surface cannot be effectively supplied under ordinary conditions. But under supercritical conditions, the scarce $\mathrm{Ni}^{2+}$ on the surface of the electrodepositing film can be effectively supplied due to better diffusivity [8]. As the electrodepositing process continues, the thickness of the electrodepositing film increases, while inside, the height of micro groove decreases, and the $\mathrm{Ni}^{2+}$ can spread more easily to the surface of electrodepositing film because of the shorter diffusion distance.

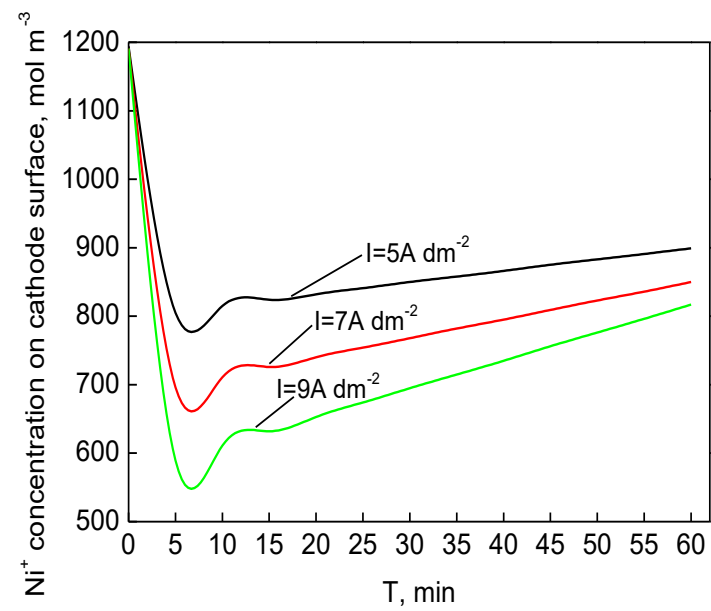

a

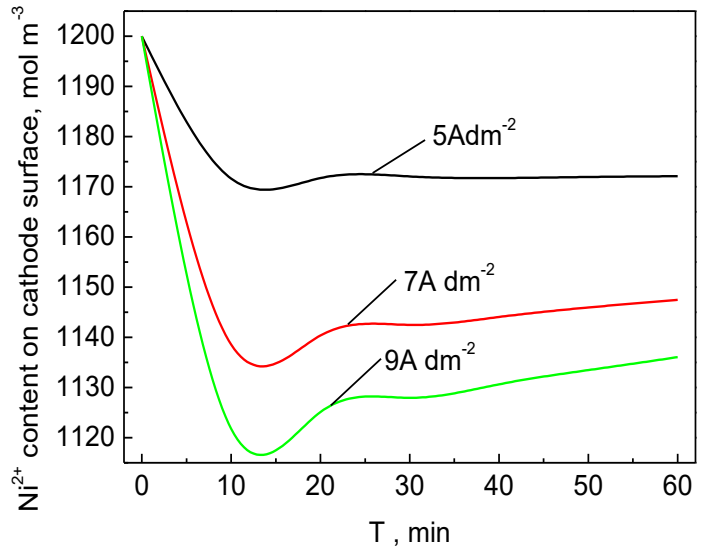

b

Fig. 4. Average $\mathrm{Ni}^{2+}$ concentration on cathode surface under different current density: $a$-ordinary condition; $b-\mathrm{SCF}$ $\mathrm{CO}_{2}$ condition

\subsection{Electroforming layer thickness}

The simulating thickness of the electrodepositing film is shown in Fig. 5 a when the working time is $60 \mathrm{~min}$ and the current density is $900 \mathrm{~A} / \mathrm{m}^{2}$. It can be seen that the thickness distribution of the electrodepositing film is relatively stable in the middle, but peaks at the edges, similar to that of the current density distribution shown in Fig. 5 b. It can be seen from Fig. $5 \mathrm{c}$ that with the increase of current density, the average thickness of the electrodepositing film is greater, and thickness of the electrodepositing film grows linearly at the same current 
density. This is because the $\mathrm{Ni}^{2+}$ concentration on the surface of the electrodepositing film can be replenished quickly, and the middle part of the micro film is flat due to the excellent diffusion environment in the supercritical condition. Nickel ions deposit substantially on the edge of microgroove due to the current edge effect and the ion mass transfer limitations of the microgroove, resulting in the lack of nickel ions between the edge and central area of electrodepositing film.

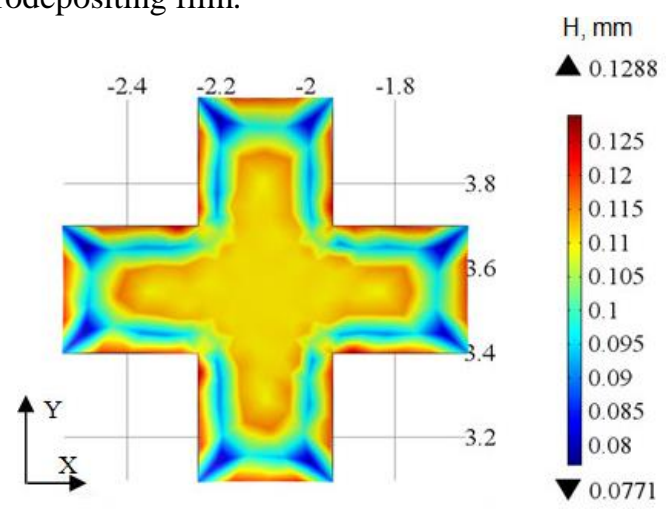

a

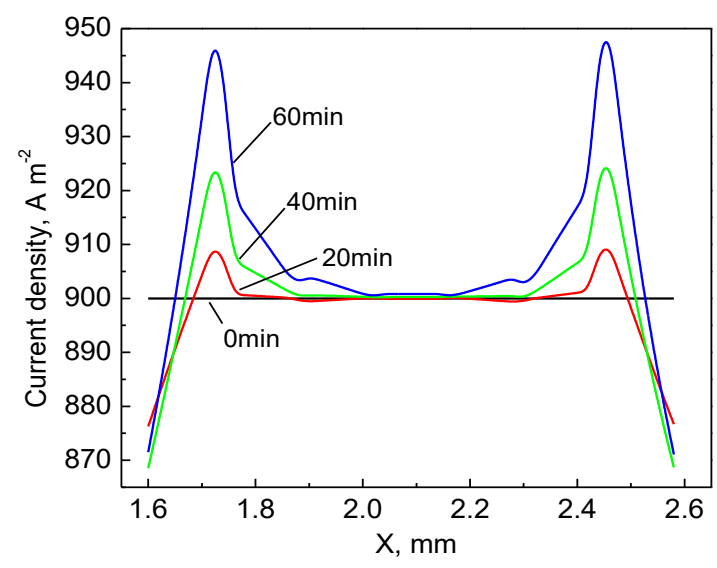

$\mathrm{b}$

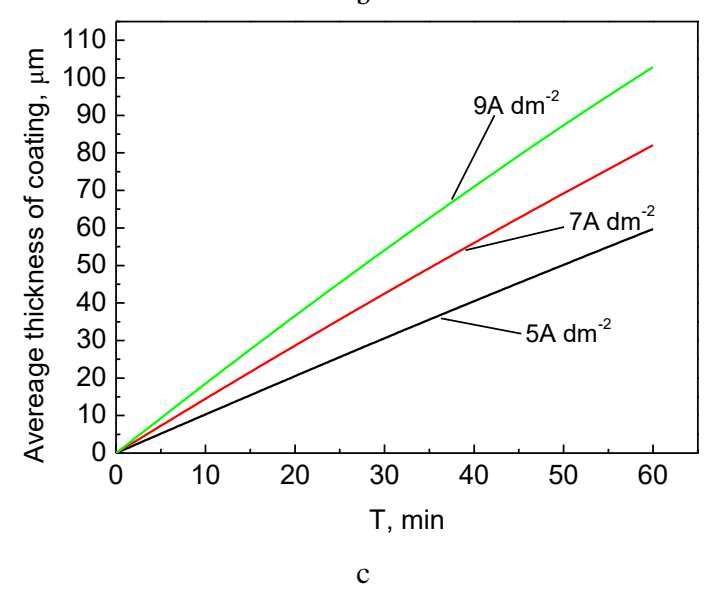

Fig. 5. Thickness changes of electrodepositing films under different current densities: $\mathrm{a}-\mathrm{I}=900 \mathrm{~A} / \mathrm{m}^{2}, \mathrm{~T}=60 \mathrm{~min}$, thickness distribution of electrodepositing film; $\mathrm{b}$-current density distribution in the middle of electrodepositing film; c-average thickness of electrodepositing films under different current densities

This means that wrinkles form easily. As time goes on, the $\mathrm{Ni}^{2+}$ on wrinkles cannot be supplied effectively, and the electrodepositing rate slows, causing the electrodepositing film becoming uneven at the edges like the current density distribution.

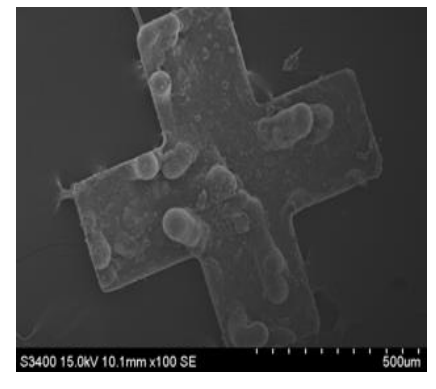

a

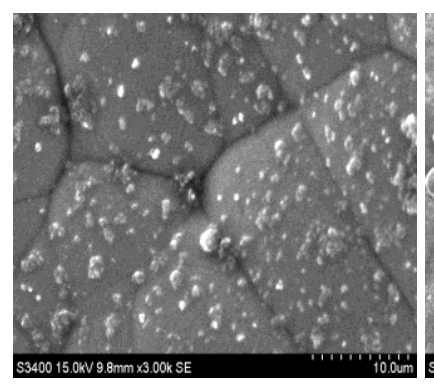

$\mathrm{c}$

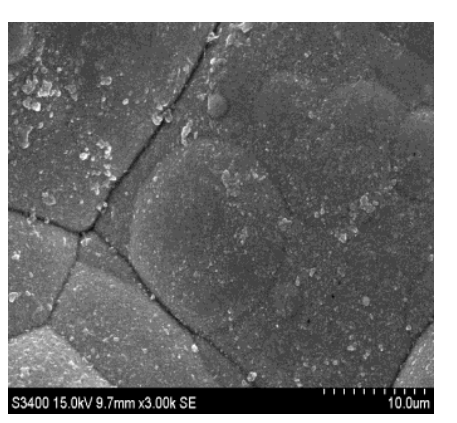

e

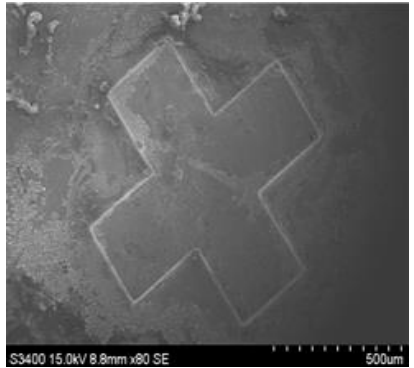

b

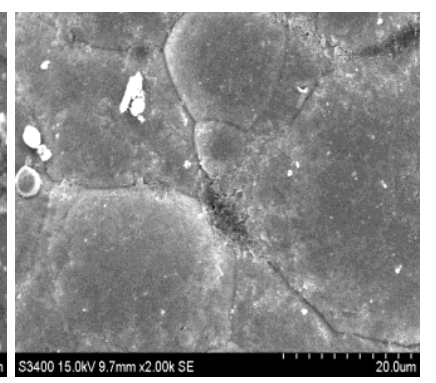

$\mathrm{d}$
Fig. 6. SEM images of Nickel-diamond electrodepositing composite minuteness films: $\mathrm{a}$-ordinary condition; $\mathrm{b}-$ SCF-CO 2 condition; c-SCF-CO $2,500 \mathrm{~A} / \mathrm{m}^{2} ; \mathrm{d}-\mathrm{SCF}-$ $\mathrm{CO}_{2}, 700 \mathrm{~A} / \mathrm{m}^{2} ; \mathrm{e}-\mathrm{SCF}-\mathrm{CO}^{2}, 900 \mathrm{~A} / \mathrm{m}^{2}$

\section{TEST ANALYSIS}

\subsection{Morphology of micro electrodepositing film}

A self-developed supercritical electrodepositing device was used. Before the test, pre-dispersion treatment of electrodepositing solution must be carried out to make the nano-particles wetted sufficiently and dispersed uniformly in the bath. A nickel-diamond micro composite was prepared by electrodepositing technology under different current densities. Its surface is shown in Fig. 6.

The ordinary condition and the $\mathrm{SCF}-\mathrm{CO}_{2}$ condition are shown in Fig. 6 a and $b$ respectively. The different current densities of $500 \mathrm{~A} / \mathrm{m}^{2}, 700 \mathrm{~A} / \mathrm{m}^{2}$, and $900 \mathrm{~A} / \mathrm{m}^{2}$ in the $\mathrm{SCF}-\mathrm{CO}_{2}$ condition are shown in Fig. $6 \mathrm{c}, \mathrm{d}$ and e. When contrasting Fig. 6 a and b, it can be seen that the surface of the micro electrodepositing film prepared in the $\mathrm{SCF}-\mathrm{CO}_{2}$ is level, but the samples prepared in ordinary condition have uneven surfaces. It can be seen from Fig. $6 \mathrm{c}-\mathrm{e}$ that the micro electrodepositing film is flat, unit cells clearly appear, and the nano-diamond particles are dispersed evenly on the microscopic surface. The reason is that 
particle mass transfer relies mainly on the diffusion in micro grooves. Also, the $\mathrm{SCF}-\mathrm{CO}_{2}$ electrodepositing system was provided with very high diffusivity and wettability to restrain the reunion of nano-diamond particles. Nickel ions can co-deposit well with diamond particles and the simulated thickness values are similar to the measured thickness values. It means that the micro composite prepared by the electrodepositing method in the $\mathrm{SCF}-\mathrm{CO}_{2}$ has the advantages of surface morphology, grain size, and compact structure.

\subsection{Microhardness of micro electrodepositing film}

The samples were tested for their micro-hardness values. It can be found that when the current density is $700 \mathrm{~A} / \mathrm{m}^{2}$, the electrodepositing temperature is $323 \mathrm{~K}$, the supercritical pressure is $12 \mathrm{MPa}$, the nano-diamond particle is $30 \mathrm{~g} / \mathrm{L}$, and the micro-hardness of micro electrodepositing composite reaches $900.75 \mathrm{HV}$ (200 g). When the current density is $900 \mathrm{~A} \mathrm{~m}^{-2}$, the micro-hardness decreases to $868.3 \mathrm{HV}(200 \mathrm{~g})$, which is greater than that of the ordinary condition of $530 \mathrm{HV}(200 \mathrm{~g})$ measured from contrast test sample. It shows that the Ni-diamond micro composite has a better micro-hardness. At the same time, the influence of the current density on the microhardness of the composite and the internal essence also need to be explored further.

\section{CONCLUSIONS}

Comsol software was used to simulate an electric field and the ion mass transfer of a micro electrodepositing system in $\mathrm{SCF}-\mathrm{CO}_{2}$. The results show that the electric field inside the micro groove distributes evenly. The average $\mathrm{Ni}^{2+}$ concentration on the surface of the electrodepositing film is more stable than that of the ordinary condition due to excellent mass transfer performance in $\mathrm{SCF}-\mathrm{CO}_{2}$. The thickness of the electrodepositing film is directly proportionate to the current density. The middle part of the micro sample is generally flat, but peaks occur on the edges of the sample distribution, which is similar to the distribution of the current density.

Compared with the ordinary electrodepositing method, the surface morphology of the Ni-diamond micro electrodepositing composite prepared in the $\mathrm{SCF}-\mathrm{CO}_{2}$ is smooth and compact. When supercritical pressure is $12 \mathrm{MPa}$, the temperature is $323 \mathrm{~K}$, and the current density is $700 \mathrm{~A} / \mathrm{m}^{2}$, the micro-hardness of the Ni-diamond micro composite can reach up to $900.75 \mathrm{HV}$ (200 g)

\section{Acknowledgments}

This project was supported by the National Natural Science Foundation of China (No.51275222) and Natural Science Foundation of Jiangsu Province (No.BK20161198).

\section{REFERENCES}

1. Qu, N.S., Zhu, D., Lei, W.N. Ni-CeO 2 Nanocomposite Deposits Obtained by Electroforming China Mechanical Engineering 16 (z1) 2005: pp. $441-443$.

2. Kim, Y.H., Bae, C.W., Kim, D.W. The Surface Improvement by Supercritical Nanoplating Transactions of the Korean Society of Mechanical Engineers A 33 (9) 2009: pp. $913-921$. https://doi.org/10.3795/KSME-A.2009.33.9.913

3. Hong, K.M., Kim, M.S., Chung, J.G. Characteristics of a Nickel Film Electroplated on a Copper Substrate in Supercritical $\mathrm{CO}_{2}$ Journal of Industrial and Engineering Chemistry 10 (2) 2004: pp. 683-689. 10.4028/www.scientific.net/JMNM.23.247

4. Mark, C.T., Masato, S., Akinobu, S., Chiemi, I., Yakichi, H. Bright Nickel Film Deposited by Supercritical Carbon Dioxide Mulsion Using Additive-Free Watts Bath Electrochimica Acta 55 (22) 2010: pp. 6469-6475. https://doi.org/10.1016/j.electacta.2010.06.037

5. Hong, K.M., Kim, M.S., Yong, C.L. The Characteristics of Nickel-Electroplated on Copper Substrate in Supercritical $\mathrm{CO}_{2}$ Fluid Metal Stable Nano-crystal Material 23 (3) 2005: pp. 247-250.

6. Nguyen, V.C., Lee, C.Y., Chang, L., Chen, F.J., Lin, C.S. The Relationship between Nano Crystallite Structure and Internal Stress in Ni Coatings Electrodeposited by Watts Bath Electrolyte Mixed with Supercritical $\mathrm{CO}_{2}$ Journal of The Electrochemical Society 159 (6) 2012: pp. 393-399. https://doi.org/10.1149/2.061206jes

7. Liu, W.Q., Lei, W.N., Qu, N.S., Li, X.P., Liu, Y.F. Progress in Study of Nanomaterials Preparation by Electroplating in $\mathrm{SCF}-\mathrm{CO}_{2}$ Rare Metal Material Engineering 39 (11) 2010: pp. 2064-2067.

8. Lei, W.N., Wang, X.X., Liu, W.Q., Chen, G.Y., Jiang, B. Diffusion Transport Modeling and Numerical Analysis of Micro-elecforming under Supercritical $\mathrm{CO}_{2}$ Fluid China Mechanical Engineering 23 (19) 2012: pp. 2351-2356. https://doi.org/10.3969/j.issn.1004-132X.2012.19.017

9. Li, D. Electrochemical Principle. Beijing University of Aeronautics and Astronautics Press, Beijing, 2008: pp. $172-174$.

10. Shao, L.G., Du, L.Q., Liu, C. Numerical Analysis and Experiment of Current-fluid Coupling in Microelectroforming Optics and Precision Engineering 17 (9) 2009: pp. 2184-2190.

11. Wang, Y., Kang, M. Research on Anode Design of Jetelectrodeposition Based on COMSOL China Mechanical Engineering 25 (9) 2014: pp. 1180-1185. 10.3969/j.issn.1004-132X.2014.09.009

12. Yang, H., Chen, R., Tsai, T.H., Chang, J.C., Wu, J.C. High-aspect-ratio Microstructural Posts Electroforming Modeling and Fabrication in LIGA Process Microsystem Technologies 12 (3) 2006: pp. 187-192. https://doi.org/10.1007/s00542-005-0050-6

13. Ming, P., Zhu, D., Hu, Y.Y., Zeng, Y.P. Numerical Analysis on Mass Transport in Micro Electroforming of Micro Structures with High-aspect-ratio Chinese Journal of Mechanical Engineering 44 (8) 2008: pp. 195-201. 